\title{
Regional, demographic and national influences on attitudes and beliefs with regard to physical activity, body weight and health in a nationally representative sample in the European Union
}

\author{
Anthony Kafatos ${ }^{1}$, Yannis Manios ${ }^{1}$, Irini Markatii ${ }^{1}$, Ismene Giachetti ${ }^{2}$, \\ Maria Daniel Vaz de Almeida ${ }^{3}$ and Lars Magnus Engstrom ${ }^{4}$ \\ ${ }^{1}$ Faculty of Medicine, University of Crete, PO Box 1393, Heraklion, Crete, Greece: ${ }^{2}$ CPC France, \\ 379 Avenue du General de Gaulle, 92140 Clamart, France: ${ }^{3}$ Curso de Cienceias da Nutricao, \\ Rua do Dr Roberto Frias, 4000 Porto, Portugal: ${ }^{4}$ Stockholm Institute of Education, Department of \\ Educational Research, PO Box 34103, S-100 26 Stockholm, Sweden
}

\begin{abstract}
Introduction: Although the benefits of physical activity regarding body-weight gain and health in general are now widely accepted, physical activity levels remain low among citizens in the western world. This could be attributed to certain attitudes and beliefs about physical activity. Identifying and understanding these parameters would be the first step in an attempt to increase the levels of physical activity in populations generally characterized as having a sedentary lifestyle.

Objective: The aim of the present study was to identify the attitudes and beliefs regarding physical activity, body weight and health in a nationally representative sample in the EU and in particular to explore the demographic and national (cultural) influences on attitudes towards physical activity.

Design: In each member state of the EU, approximately 1000 adults aged 15 years and over, were selected to complete an interviewer-assisted face-to-face questionnaire. Overall, a sample of 15239 individuals in the EU participated in the study. Subject selection was quota-controlled to ensure samples in each country were nationally representative.

Results: On a European level wide variations were observed regarding the levels, beliefs and attitudes towards physical activity. More positive beliefs were observed among Finns, while less positive beliefs were observed among southern Europeans. A similar pattern was observed for attitudes, with the Portuguese having the highest percentage feeling that they do not need to be more physically active than they already are. However, most southern Europeans felt that a campaign would encourage them to become more active than they already are. On a demographic level, the youngest, more educated and most physically active subjects had more positive attitudes and beliefs towards physical activity and the health benefits derived from it; while for the overweight, beliefs and attitudes toward physical activity were related primarily to the benefits related to weight control.

Conclusions: Lower levels of physical activity, an unwillingness to become active among non-participants and confusion regarding the weight gain benefits and general health benefits of exercise were reported more frequently among southern Europeans and older and less educated subjects. The Finns scored highest in all these parameters, possibly due to the programmes implemented and the beliefs and behaviour changes observed in this country during the last few years. The actions taken in Finland and their benefits could be employed appropriately in the other European states.
\end{abstract}

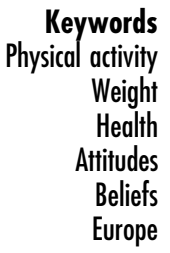

Hippocrates first reported that a sedentary lifestyle was detrimental to health. Many years later, in 1700, Bernandino Ramazzini published a treatise concerning the health hazards of tailors compared with those of messengers ${ }^{1}$. However, cardiovascular diseases (CVDs) were not known until 1912 and their relationship with levels of physical activity was not found until 1953. The first epidemiological study, conducted by Morris and his colleagues in $1953^{2,3}$, was based on the reported CVD risk factors in bus drivers and conductors. The 
former spent many hours per day sitting behind the wheel while the latter spent many hours walking up and down stairs. Conductors were found to have much lower risk for CVD compared with the drivers. After this study other studies conducted on letter-carriers and mail clerks $^{4}$, farmers and sedentary townsmen ${ }^{5,6}$, railroad track workers and clerks ${ }^{7,8}$ and longshoremen loading cargo into ships or tallying it into warehouses ${ }^{9,10}$ reached similar conclusions.

Today, it is well known that physical inactivity is related to an increased risk for $\mathrm{CVD}^{11}$ and also to other disease states such as hypertension, non-insulin-dependent diabetes mellitus, osteoporosis, obesity and certain forms of cancer $^{12}$. Furthermore, a reduction in agestandardized mortality rates in initially sedentary men who became more active has been found ${ }^{13,14}$. A sedentary lifestyle is prevalent in most industrial countries but no direct comparison between countries has been previously possible due to differences in sampling and assessment methods. However, findings from the USA could be used as indications of what is going on in other industrial countries. It has been estimated that 250000 deaths per year in the USA could be attributed to physical inactivity ${ }^{15}$, while $35 \%$ of coronary heart disease deaths, $35 \%$ of diabetes deaths and $32 \%$ of colon cancer deaths are due to sedentary lifestyle ${ }^{16}$. These findings support the public health importance of increasing the levels of physical activity in the general population.

However, before implementing a pan-European campaign or an intervention aiming to increase the levels of physical activity in Europe, a survey is needed to examine the attitudes of Europeans on relevant issues. The present survey on consumers' attitudes towards physical activity, body weight and health is the first study to examine the attitudes of EU consumers, from all 15 member states, in addition to having a measure of prevailing reported levels of activity, inactivity and self-reported body weight. This paper will focus on the findings related to attitudes towards physical activity, body weight and health in the EU, and in particular the influences of sociodemographics and culture on these attitudes.

\section{Methods}

From each member state of the EU, approximately 1000 adults, aged 15 years and over, were selected to complete the interviewer-assisted face-to-face questionnaire. A general description of the sampling methods used in the survey and also the design of the questionnaire are presented elsewhere in this supplement ${ }^{17}$. The findings of the present report are based on the responses obtained from nine questions/statements.

The first question aimed to assess what factors are perceived to be important in influencing an individual's health. Physical activity was listed along with eight other factors and subjects were asked to select two of these factors which, according to their beliefs, have the greatest influence on overall health.

The second question sought to identify which factors subjects personally believe influence their ability to gain weight. A list of seven factors, including physical activity, was provided, but as this question was directed at the subject personally, the options of 'do not tend to put on weight' and 'other' were also given.

For the final seven questions/statements subjects were asked to indicate their level of agreement or disagreement with the statement along a four-point Likert scale-ranging from 'strongly agree' to 'strongly disagree'. For the needs of the present study the responses of 'strongly agree' and 'tend to agree' were combined together as 'agree', and the responses of 'strongly disagree' and 'tend to disagree' were combined together as 'disagree'. These questions/ statements were worded as follows.

- 'Physical activity/exercise has numerous beneficial effects on health'.

- 'Being $13 \mathrm{~kg}$ heavier than I am now would be a risk to my health'.

- 'Unless physical activity/exercise results in weight loss, a person is not really benefiting from it'.

- 'I do not need to do more physical activity/exercise than I already do'.

- 'Most of my friends take plenty of exercise'.

- 'Health professionals, e.g. doctors, are good sources of information on the health benefits of physical activity/exercise'.

- 'A campaign in my locality aimed at increasing participation in physical activity/exercise would be effective in encouraging me to do more'.

The national samples were weighted by demographic factors for representativeness. In order to consider overall EU results, national profiles were combined using a correction factor for population size. Due to the quantitative nature of the present area of investigation, only descriptive statistics are presented in this paper. The artificial increase in sample size due to the EU weightings excluded the possibility of hypothesis testing of demographic groups across the EU.

\section{Results}

The average percentage of subjects from all European member states regarding the factors perceived to be among the two most important influences on health are presented in Table 1. Smoking, food and stress are the three most important factors perceived to have the greatest influence on health in the EU-ahead of physical activity and body weight which ranked fifth 
Table 1 Percentage of subjects in each member state selecting factors perceived to be among the two most important influences on health

\begin{tabular}{|c|c|c|c|c|c|c|c|c|}
\hline Country & Smoking & Food & Stress & $\begin{array}{l}\text { Alcohol } \\
\text { intake }\end{array}$ & $\begin{array}{l}\text { Physical } \\
\text { activity }\end{array}$ & Environment & $\begin{array}{l}\text { Body } \\
\text { weight }\end{array}$ & $\begin{array}{c}\text { Genetics and } \\
\text { metabolism }\end{array}$ \\
\hline Austria & 36 & 54 & 21 & 27 & 23 & 16 & 9 & 9 \\
\hline Belgium & 38 & 51 & 30 & 15 & 15 & 11 & 21 & 6 \\
\hline Denmark & 19 & 62 & 17 & 4 & 36 & 15 & 11 & 7 \\
\hline Finland & 35 & 40 & 13 & 18 & 44 & 9 & 11 & 7 \\
\hline France & 32 & 32 & 42 & 20 & 13 & 20 & 14 & 10 \\
\hline Germany & 30 & 53 & 26 & 18 & 20 & 20 & 13 & 12 \\
\hline Greece & 63 & 23 & 49 & 15 & 9 & 13 & 16 & 9 \\
\hline Ireland & 45 & 32 & 31 & 15 & 31 & 9 & 19 & 10 \\
\hline Italy & 53 & 27 & 44 & 28 & 9 & 15 & 9 & 8 \\
\hline Luxembourg & 50 & 29 & 28 & 35 & 11 & 23 & 9 & 5 \\
\hline Netherlands & 52 & 48 & 27 & 15 & 16 & 11 & 13 & 14 \\
\hline Portugal & 26 & 60 & 21 & 17 & 11 & 21 & 16 & 4 \\
\hline Spain & 48 & 41 & 25 & 31 & 15 & 12 & 8 & 4 \\
\hline Sweden & 38 & 29 & 33 & 15 & 31 & 15 & 13 & 14 \\
\hline UK & 46 & 26 & 37 & 15 & 25 & 13 & 15 & 9 \\
\hline EU average* & 41 & 38 & 33 & 20 & 18 & 16 & 13 & 9 \\
\hline
\end{tabular}

*Weighted according to population size.

and seventh, respectively. Considerable interstate variation existed in the percentage of subjects selecting physical activity, ranging from as high as $44 \%$ in Finland to as low as 9\% in Greece and Italy, where the first risk factor on the list appeared to be smoking with $63 \%$ and $53 \%$, respectively (the highest percentages for smoking among all the EU countries). However, when subjects were asked to agree or disagree with the statement 'physical activity/exercise has numerous beneficial effects on health' there was an overwhelming level of agreement in all member states (average 96\%), with a small range of just $8 \%$ between the lowest (Belgium 91\%) and the highest (Greece 99\%) levels. Such a level of homogeneity between member states was also observed across EU demographics.

With respect to body weight, up to $78 \%$ of the EU sample agreed with the statement that being $13 \mathrm{~kg}$ heavier than I am now would be a risk to my health'. The subjects more likely to agree with this statement were females, older, less educated and either overweight or obese. The strong influence of age on the level of agreement with this statement in the EU was seen in the sizeable increase in the proportion agreeing among the 55 year olds and over (87\%), compared with the 15-34 year olds (69\%) and was reflected in all 15 member states. Similarly, the percentages of agreement increased from $55 \%$ and $75 \%$ for the underweight and normal weight, to $87 \%$ and $92 \%$ for the overweight and obese, respectively.

Table 2 presents the factors perceived as having the greatest influence on personal weight gain in the 15 member states. Physical activity was the fifth most frequently selected influence on personal weight gain, although there was wide variation between member

Table 2 Percentage of subjects in each member state selecting factors perceived to be among the two most important influences on personal weight gain

\begin{tabular}{|c|c|c|c|c|c|c|c|}
\hline Country & Food & Fat & Sugar & Genetics & $\begin{array}{l}\text { Physical } \\
\text { activity }\end{array}$ & $\begin{array}{l}\text { Alcohol } \\
\text { intake }\end{array}$ & $\begin{array}{l}\text { Do not tend to } \\
\text { put on weight }\end{array}$ \\
\hline Austria & 51 & 38 & 26 & 24 & 19 & 8 & 9 \\
\hline Belgium & 42 & 42 & 33 & 13 & 11 & 14 & 13 \\
\hline Denmark & 43 & 54 & 7 & 23 & 27 & 7 & 18 \\
\hline Finland & 49 & 32 & 10 & 23 & 51 & 3 & 18 \\
\hline France & 43 & 41 & 25 & 13 & 19 & 15 & 18 \\
\hline Germany & 45 & 40 & 27 & 21 & 17 & 12 & 15 \\
\hline Greece & 56 & 44 & 20 & 15 & 9 & 12 & 15 \\
\hline Ireland & 44 & 37 & 21 & 13 & 26 & 13 & 22 \\
\hline Italy & 50 & 37 & 21 & 26 & 9 & 7 & 17 \\
\hline Luxembourg & 37 & 35 & 22 & 16 & 13 & 10 & 24 \\
\hline Netherlands & 45 & 40 & 18 & 25 & 20 & 13 & 16 \\
\hline Portugal & 34 & 44 & 23 & 10 & 11 & 12 & 22 \\
\hline Spain & 44 & 51 & 19 & 19 & 12 & 9 & 18 \\
\hline Sweden & 48 & 30 & 19 & 19 & 33 & 2 & 22 \\
\hline UK & 34 & 29 & 21 & 12 & 21 & 14 & 24 \\
\hline EU average* & 44 & 39 & 22 & 18 & 17 & 11 & 18 \\
\hline
\end{tabular}

*Weighted according to population size. 
Table 3 Percentage of EU subjects selecting 'physical activity/ exercise' as an important influence on weight gain classified by education level and age group

\begin{tabular}{lccc}
\hline & \multicolumn{3}{c}{ Education level } \\
\cline { 2 - 4 } Age group (years) & Primary & Secondary & Tertiary \\
\hline $15-34$ & 13 & 17 & 31 \\
$35-54$ & 12 & 17 & 23 \\
$55+$ & 12 & 14 & 22 \\
\hline
\end{tabular}

states. In Finland physical activity was the most frequently selected influence with over $50 \%$ of Finns selecting it, while in Greece and Italy this factor was selected by only 9\%. With increasing educational level there is an increase in the percentage of subjects selecting 'physical activity/exercise' in all three age group levels, although the rate of increase was greater in the youngest age group compared to the other two age groups (Table 3).

When examining the percentage of subjects in the EU selecting the most important influence on personal weight gain in terms of their participation level in physical activity in a typical week (non-participants and the most active 10\%), the largest difference between these two groups was in the selection of 'physical activity/exercise' as an influence, with the non-active participants being half as likely to select this variable (11\%) compared with the most active participants (22\%) (Table 4).

Although almost all of the EU sample (96\%) agreed that physical activity has numerous beneficial effects on health, only 69\% disagreed that 'unless physical activity/exercise results in weight loss, a person is not really benefiting from it'. Member states varied considerably in their level of agreement with this statement, ranging from as little as $9 \%$ in Italy to as much as $44 \%$ in Portugal. No such great variation was observed across EU demographics. There were no

Table 4 Percentage of EU subjects selecting the most important influences on personal weight gain classified by participation level in various physical activities during a typical week

\begin{tabular}{lcc}
\hline Weight factors & $\begin{array}{c}\text { Non-participants } \\
\text { (did not } \\
\text { Most active } \\
\text { participants } \\
\text { (top 10\%) }\end{array}$ & $\begin{array}{c}\text { partipate in } \\
\text { any phycal } \\
\text { activity) }\end{array}$ \\
\hline Food & 44 & 43 \\
Fat & 36 & 40 \\
Sugar & 21 & 24 \\
Genetics & 17 & 19 \\
Physical activity & 22 & 11 \\
Alcohol intake & 11 & 11 \\
Do not tend to put on weight & 20 & 17 \\
Smoking & 3 & 5 \\
None & 3 & 3 \\
Do not know & 2 & 3 \\
\hline
\end{tabular}

Table 5 Percentage of subjects in each member state who agree with the statement 'unless physical activity/exercise results in weight loss, a person is not really benefiting from it' classified by education level

\begin{tabular}{lccc}
\hline Country & Primary & Secondary & Tertiary \\
\hline Austria & 26 & 22 & 9 \\
Belgium & 21 & 22 & 15 \\
Denmark & 24 & 11 & 11 \\
Finland & 28 & 19 & 10 \\
France & 46 & 35 & 24 \\
Germany & 29 & 33 & 25 \\
Greece & 43 & 26 & 21 \\
Ireland & 23 & 19 & 10 \\
Italy & 11 & 8 & 8 \\
Luxembourg & 26 & 18 & 8 \\
Netherlands & 32 & 26 & 9 \\
Portugal & 49 & 35 & 36 \\
Spain & 26 & 21 & 16 \\
Sweden & 20 & 13 & 10 \\
UK & 42 & 31 & 17 \\
EU average* & 30 & 25 & 18 \\
\hline
\end{tabular}

*Weighted according to population size.

differences between males and females and only a small increase with increasing age. In contrast, there was quite a strong influence of education level. As education level increased from primary to tertiary the percentage of subjects agreeing with the statement decreased from $30 \%$ to $18 \%$ (Table 5). Similarly underweight (22\%) and normal weight (23\%) subjects were less likely to agree with the statement compared with the overweight (28\%) and obese (32\%).

Over one-third of the EU subjects (37\%) agreed with the statement that 'most of my friends take plenty of exercise'. Large geographic differences were evident, with Finland having $68 \%$ of its sample agreeing that most of their friends take plenty of exercise while Greece and Spain had only 28\% agreeing. Differences between sexes were very small although in the majority of the member states more males agreed with the statement than females. In 14 out of 15 member states more young people (15-34 year olds) agreed that most of their friends take plenty exercise (46\%) compared to the oldest age group (55+ year olds) (30\%). Finland was the only exception with there being no difference between age groups (all 68\%). A very clear difference existed between the most active participants and nonactive participants; this relationship was apparent in all member states, except the Netherlands, where 34\% of both the most active participants and non-active participants agreed with the statement. As many as $43 \%$ of those with a primary-level education who felt that most of their friends do not take plenty of exercise, are not physically active themselves, while among the tertiary-educated subjects in the EU who agreed that most of their friends take plenty of exercise, half of them are physically active (Table 6). Thus one's educational background and whether one's friends 
Table 6 Percentage of EU subjects who agree/disagree with the statement 'most of my friends take plenty of exercise' classified by education level and physical activity level

\begin{tabular}{lccccc}
\hline & \multicolumn{2}{c}{ Primary } & & \multicolumn{2}{c}{ Tertiary } \\
\cline { 2 - 3 } \cline { 5 - 6 } Physical activity level & Disagree & Agree & & Disagree & Agree \\
\hline $\begin{array}{l}\text { Inactive and not } \\
\begin{array}{l}\text { considering becoming } \\
\text { physically active }\end{array}\end{array}$ & 43 & 29 & & 25 & 16 \\
\begin{tabular}{l} 
Quite physically active \\
\hline
\end{tabular} & 21 & 36 & & 39 & 50 \\
\hline
\end{tabular}

take plenty of exercise may be good predictors of a person's own physical activity level.

Almost half of the EU sample (47\%) agreed with the statement 'I do not need to do more physical activity/ exercise than I already do'. Older subjects and those with a primary-level education were more likely to agree that they do not need to do more exercise than they already do, in spite of the fact that these are the very population groups who are less active. The largest demographic effects may be seen in educational level. Over half of these with a primary-level education felt they do not need to be more active than they already are compared with just over a third of those with a tertiary-level education (Table 7). In addition, the percentage of subjects not participating in leisuretime physical activity and spending 7 hours or more during weekends sitting down was higher for those with a primary-level education (Table 8). The percentage of those doing work-related physical activity was higher among those with a primary-level education compared to those with tertiary education (Table 8).

When subjects were asked whether or not 'health professionals are good sources of information on the health benefits of physical activity/exercise' almost three-quarters $(74 \%)$ of the EU sample agreed. The responses (agree/disagree) were fairly homogenous in all member states and no differences between sexes or between age groups were observed. With increasing education level, there was a decreasing likelihood of agreeing with the statement, though these differences were quite small (Table 9).

Wide interstate variation was observed regarding
Table 7 Percentage of EU subjects agreeing with the statement 'I do not need to do any more physical activity/exercise than I already do' classified by demographics (sex, age and education level)

\begin{tabular}{lc}
\hline & Per cent agreeing \\
\hline Sex & \\
Male & 50 \\
Female & 43 \\
Age (years) & \\
$15-34$ & 42 \\
$35-54$ & 43 \\
$55+$ & 58 \\
Education level & \\
Primary & 59 \\
Secondary & 46 \\
Tertiary & 38 \\
\hline
\end{tabular}

responses to the statement 'a campaign in my locality aimed at increasing participation in physical activity/ exercise would be effective in encouraging me to do more'. As few as $21 \%$ from Austria and the Netherlands agreed that local campaigns would be effective in encouraging them to do more. In contrast, the highest percentages of agreement were obtained in the southern European countries, Greece and Portugal, with $68 \%$ and 63\%, respectively (Table 10). No differences between sex and educational levels were observed, while with increasing age there was a decrease in the percentage of EU subjects agreeing about the value of local campaigns.

\section{Discussion}

A variety of questions were used in order to assess the beliefs and attitudes of the population, and further analysis of the responses took place in order to search for differences at a national level and between demographic groups. For the purpose of the present study only a part of these findings are presented and discussed, particularly those which could lead to certain conclusions regarding Europeans' beliefs and attitudes on the issues examined. Emphasis was placed on the differences found between member states and demographic groups (i.e. cultural versus

Table 8 Percentage of EU subjects agreeing with the statement 'I do not need to do any more physical activity/exercise than I already do' classified by activity levels during leisure time and at work and education level

\begin{tabular}{lcccc}
\hline Education level & $\begin{array}{c}\text { Do not participate in } \\
\text { leisure-time activities }\end{array}$ & $\begin{array}{c}\text { Sitting in leisure } \\
\text { time for } 7 \text { hours or more } \\
\text { at the weekend }\end{array}$ & $\begin{array}{c}\text { Being active at } \\
\text { work for }>3 \text { hours } \\
\text { (doing more than } \\
\text { sitting and walking) }\end{array}$ & $\begin{array}{c}\text { Sitting at } \\
\text { work for } \\
>6 \text { hours }\end{array}$ \\
\hline Primary & 40 & 63 & 16 & 13 \\
Secondary & 29 & 29 & 16 & 20 \\
Tertiary & 22 & 22 & 9 & 29 \\
\hline
\end{tabular}


Table 9 Percentage of EU subjects agreeing with the statement 'health professionals are good sources of information on the health benefits of physical activity/exercise' classified by demographics (sex, age and education level)

\begin{tabular}{lc}
\hline & Per cent agreeing \\
\hline Sex & \\
Male & 74 \\
Female & 74 \\
Age (years) & \\
15-34 & 73 \\
$35-54$ & 72 \\
$55+$ & 77 \\
Education level & \\
Primary & 78 \\
Secondary & 73 \\
Tertiary & 70 \\
\hline
\end{tabular}

demographic influences). These differences may enhance our understanding on these issues, relating the findings to the different needs and perceptions between states and sociodemographic groups. Identifying the differences between these groups will also help us to design the most appropriate and effective interventions in order to enhance the levels of leisure-time physical activity in these groups at a pan-European or regional level.

The fact that physical activity was the most frequently selected influencing factor in Finland compared with any other member state more than probably reflects the many programmes that promote physical activity in this country which have been going on for several years ${ }^{18}$, as well as the increased levels of physical activity for the overall population observed in Finland over the last decade $^{18,19}$. On the other hand the low percentage of responses observed in Greece and Italy, but also in the

Table 10 Percentage of subjects in each member state who agree or disagree with the statement 'a campaign in my locality aimed at increasing participation in physical activity/exercise would be effective in encouraging me to do more'

\begin{tabular}{lccc}
\hline Country & Agree & Disagree & Do not know \\
\hline Austria & 21 & 73 & 6 \\
Belgium & 33 & 57 & 10 \\
Denmark & 40 & 54 & 6 \\
Finland & 40 & 59 & 1 \\
France & 37 & 56 & 7 \\
Germany & 28 & 62 & 10 \\
Greece & 68 & 27 & 5 \\
Ireland & 54 & 42 & 4 \\
Italy & 43 & 50 & 7 \\
Luxembourg & 34 & 58 & 8 \\
Netherlands & 22 & 74 & 4 \\
Portugal & 63 & 28 & 9 \\
Spain & 48 & 43 & 9 \\
Sweden & 42 & 54 & 4 \\
UK & 43 & 53 & 4 \\
EU average* & 39 & 54 & 7 \\
\hline
\end{tabular}

* Weighted according to population size. other southern European countries, is more likely related to the absence of similar programmes in these countries. Low levels of physical activity observed in these countries in earlier studies are probably also a contributing factor ${ }^{19,20}$. Greeks and Italians more frequently selected smoking as the most important factor influencing health.

One could conclude from the extremely high levels of agreement with the statement 'physical activity has numerous benefits on health' that there is no need to implement strategies to educate the public of the link between physical activity and its numerous health benefits. However, when subjects were asked to respond to more specific questions regarding the relationship of physical activity to obesity and to health, the lack of awareness of the public became apparent. On an EU level, physical activity was ranked as the fifth most important influence to prevent weight gain. There was wide interstate variation regarding the responses obtained to this statement reflecting the differences in beliefs, attitudes and behaviours between countries. In a study conducted by Steptoe et $a .^{19}$ on European students, a consistent trend between beliefs in the health benefits of exercise and participation in regular exercise was found. This association confirmed the relationship that had been observed for a wide range of behaviours and beliefs in the European Health and Behaviour Survey ${ }^{21}$ and in other studies ${ }^{22}$.

Regarding the responses obtained from different demographic groups, the oldest and the least educated subjects were less likely to select physical activity as a factor influencing body-weight gain. This finding suggests a lower level of awareness regarding the benefits of physical activity in these particular demographic groups. According to Wardle and Steptoe ${ }^{23}$, these beliefs are related to the levels of physical activity among these groups which have been found to be $\operatorname{low}^{24,25}$. Furthermore, in the present study the finding that non-active subjects are half as likely to select physical activity as an important factor influencing body weight compared with those who are physically active, confirms the finding of Steptoe et al. ${ }^{19}$ regarding the association between positive beliefs of the health benefits of exercise and exercising levels. Overweight and obese subjects were more likely to agree with the statement 'unless physical activity results in weight loss, a person is not really benefiting from it' indicating their narrower view on the benefits of physical activity as a means of losing weight.

The large geographic differences obtained in the responses to the statement 'most of my friends take plenty of exercise' reflected the average levels of physical activity of the population in each country. The Finns were most likely to agree with the statement while those from Greece and Spain were least likely to agree. 
These results confirm those of previous studies indicating that the levels of leisure-time physical activity are higher among Finns compared to southern Europeans $^{19,20}$.

In addition, the higher percentage of agreement found among the younger and the more educated subjects compared to the oldest age group and less educated subjects reflects the higher levels of leisuretime physical activity among these population subgroups. This concurs with the findings from several earlier studies ${ }^{26-29}$. Furthermore, the oldest age group and the less educated are not only the least active subgroups in the population but are also the most negative towards physical activity, reporting that they do not need to be more physically active than they already are. Regarding educational level, the percentage of subjects reporting being physically active at work (spending more than 3 hours per day doing more than walking about) was higher for those with primary education compared to those with tertiary education, most probably reflecting the manual nature of their work. Among less educated subjects the percentage of those being physically active at work is very small (16\%) compared to the percentage of agreement with the statement 'I do not need to do more physical activity than I already do' (59\%). Hence, the negative attitude of less educated subjects towards leisure-time physical activity should not necessarily be attributed to the type of work that they are involved in. It is most likely that it has to do with the overall attitude of less educated subjects towards health. This finding is supported by the fact that similar attitudes and behavioural differences between social groups have been observed for other risk factors as well $^{18,27}$

The differences detected in the present study between age groups regarding amount of leisure-time activity undertaken ${ }^{30}$, as well as perceptions about levels of activity, are in agreement with the findings of previous studies ${ }^{26}$. It seems that for younger people physical activity/sport is seen as part of their social activities $^{31}$, in contrast to the less active older age group who at the same time believe they do not need to be more physically active than they already are. In a study conducted by Owen and Bauman ${ }^{28}$ in Australia, it was found that the main reason given by older people for being less physically active is being physically unable and not wanting to exercise. According to Long et al. ${ }^{32}$ emphasizing the health benefits of simple activities such as walking, along with the provision of advice on activities appropriate to the individual's health status from medical practitioners, may enhance the physical activity levels of older people. In the present study similar percentages of all age groups believed that health professionals are a good source of information on the health benefits of physical activity. This contrasts with the findings of Booth et al. ${ }^{33}$ where more than 50\% of the oldest age group wanted advice from a health professional compared with $22 \%$ of the youngest group. However, it may be not be feasible to compare these results as the question asked was different in the two studies.

Very wide interstate variation was observed with regard to responses to the statement 'a campaign in my locality aimed at increasing participation in physical activity/exercise would be effective in encouraging me to do more'. The highest percentages of agreement were observed among southern European countries, in particular Greece and Portugal. The high level of agreement in these countries could be attributed to the absence of such programmes in these countries and to the low levels of physical activity reported ${ }^{19,20}$. Viewed optimistically, this finding could be interpreted as a willingness to increase levels of physical activity given the appropriate encouragement. However, before rushing to any conclusions and implementing campaigns in these countries, further research is needed to tease out the underlying attitudes and motives of these populations towards increased physical activity. We need to be very critical of the interpretation of responses obtained from this statement when we consider the fact that the highest percentage of agreement with the statement 'I do not need to do more physical activity than I already do' was obtained from the non-active participants in Portugal (more than $50 \%$ ). Consequently, further research is needed to determine the underlying motives of these populations, taking into account the cultural and behavioural differences within the different European member states.

The findings of the present study indicate a wide interstate and demographic variation regarding certain attitudes and beliefs towards physical activity. Identifying and understanding these differences will be the first step in developing more effective interventions for the promotion of physical activity amongst the general public. On a national level, lower levels of physical activity, a complacency towards becoming active among non-participants, and confusion regarding the health benefits of exercise beyond weight control were reported among southern European countries. The Finns, in contrast, scored higher in all these parameters possibly due to the programmes implemented and the beliefs and behavioural changes observed in this country during recent years ${ }^{18}$. On a demographic level, older and less educated subjects scored lower on these parameters and this finding is in agreement with other studies ${ }^{34}$.

In conclusion, for the promotion of physical activity different approaches should be used on a national level, taking into account policies on health promotion and health education and particularly the attitudes and 
cultural differences in each country. Regarding the youngest age group, findings from the present study indicate that they are the most active subgroup of the population, they are better informed about the health benefits of physical activity and have a more positive attitude towards physical activity. For the promotion of physical activity in this age group, emphasis has to be given more to non-health-related factors, such as having fun ${ }^{31}$, leading an exciting life ${ }^{35}$, appearance and socializing ${ }^{33,36}$. In contrast, emphasis on the health benefits of physical activity should be given in the older age groups, with the encouragement of health professionals, through simple, attractive forms of communication since confusion on these issues has been observed in the present study and elsewhere ${ }^{33}$. Emphasis should be given to simple and accessible forms of exercise, like walking, and to the direct benefits of such exercise on certain disease states ${ }^{31}$. The same applies to overweight groups, since the findings of the present study and previous studies ${ }^{19}$ indicate that losing weight is the primary motive for them to exercise. Again, simple forms of exercise and enjoyable non-competitive physical activity should be promoted for this group of people, taking into account that these individuals are more likely to drop out of exercise programmes and are less responsive to public health interventions than others ${ }^{37}$. Finally, a general approach should be used in order to encourage healthrelated behaviours among those with lower levels of education. It might be appropriate to classify the subjects of this group into two subcategories based on whether or not they are involved in manual types of work. The subjects who are physically active at work quite possibly will not be willing to increase their levels of physical activity during leisure time. However, the majority of less educated people are not involved in heavy manual work and simultaneously do not take any leisure-time physical activity. This sedentary group should be targeted when promoting physical activity.

\section{References}

1 Ramazzini B. Diseases of Workers. (Written in Latin by B Ramazzini, Professor of Physics at Padua, 1700. English edition translated by WC Wright, London, 1705.) New York: Hafner, 1964.

2 Morris JN, Heady JA, Raffle PAB, Roberts CG, Parks JW. Coronary heart disease and physical activity of work. Lancet 1953; 2: 1053-7, 1111-20.

3 Morris JN, Kagan A, Parrison DC, Gardner M, Raffle PAB. Incidence and prediction of ischaemic heart-disease in London busmen. Lancet 1966; 2: 552-9.

4 Kahn HA. The relationship of reported coronary heart disease mortality to physical activity of work. Am. J. Public Health 1963; 53: 1058-67.

5 Zukel WJ, Lewis RH, Enterline PE, et al. A short-term community study of the epidemiology of coronary heart disease: a preliminary report on the North Dakota study. Am. J. Public Health 1959; 49: 1630-9.

6 Cassel J, Heyden S, Bartel A, et al. Occupation and physical activity and coronary heart disease. Arch. Intern. Med. 1971; 128: 920-8.

7 Taylor HI, Klepetar E, Keys A, Parlin MS, Blackburn H Puchner T. Death rates among physically active and sedentary employees of the railroad industry. Am. J. Public Health 1962; 52: 1697-707.

8 Menotti A, Puddu V. Death rates among the Italian railroad employees, with special reference to coronary heart disease and physical activity at work. Environ. Res. 1976; 11: 331-42.

9 Paffenbarger RS Jr, Laughlin ME, Gima AS, Black RA. Work activity of longshoremen as related to death from coronary heart disease and stroke. N. Engl. J. Med. 1970; 282: 110914.

10 Paffenbarger RS Jr, Gima AS, Laughlin E, Black RA Characteristics of longshoremen related fatal coronary heart disease and stroke. Am. J. Public Health 1971; 61: 1362-70.

11 Blair SN. Physical activity, fitness, and coronary heart disease. In: Bouchard C, Shephard RJ, Stephens T, eds. Physical Activity, Fitness, and Health: International Proceedings and Consensus Statement. Champaign, IL: Human Kinetics, 1994; 579-90.

12 Pate RR, Pratt M, Blair SN, et al. Physical activity and public health: a recommendation from the Centers for Disease Control and Prevention and the American College of Sports Medicine. JAMA 1995; 273: 402-7.

13 Blair SN. C.H. McCloy Research Lecture. Physical activity, physical fitness, and health. Res. Q. Exerc. Sport 1993; 64: 365-76.

14 Paffenbarger RS Jr, Hyde RT, Wing AL, Lee IM, Jung DL, Kampert JB. The association of changes in physical-activity level and other lifestyle characteristics with mortality among men. N. Engl. J. Med. 1993; 328: 538-45.

15 Hahn RA, Teutsch SM, Rothenberg RB, Marks JR. Excess deaths from nine chronic diseases in the United States, 1986. JAMA 1990; 264: 2654-9.

16 Powell KE, Blair SN. The public health burdens of sedentary living habits: theoretical but realistic estimates. Med. Sci. Sports Exerc. 1994; 26: 851-6.

17 Kearney JM, Kearney MJ, McElhone S, Gibney MJ. Methods used to conduct the pan-European Union survey on consumer attitudes to physical activity, body weight and health. Public Health Nutr. 1999; 2: 79-86.

18 Lahelma E, Rahkonen O, Berg MA, et al. Changes in health status and health behavior among Finnish adults 1978-1993. Scand. J. Work Environ. Health 1997; 23: 85-90.

19 Steptoe A, Wardle J, Fuller R, et al. Leisure-time physical exercise: prevalence, attitudinal correlates, and behavioral correlates among young Europeans from 21 countries. Prev. Med. 1997; 26: 845-54.

20 Kafatos A, Mamalakis G. Policies and programs in nutrition and physical fitness in Greece. World Rev. Nutr. Diet 1993; 72: 206-7.

21 Steptoe A, Wardle J. The European Health and Behaviour Survey: the development of an international study in health psychology. Psychol. Health 1996; 11: 49-73.

22 Sallis JF, Simons-Morton BG, Stone EJ, et al. Determinants of physical activity and interventions in youth. Med. Sci. Sports Exerc. 1992; 24: S248-57.

23 Wardle J, Steptoe A. The European Health and Behaviour Survey: rationale, methods and initial results from the United Kingdom. Soc. Sci. Med. 1991; 33: 925-36.

24 Haglund BJ. Geographical and socioeconomic distribution of physical activity at work and leisure time and its relation to morbidity in a Swedish rural county. Scand.J. Soc. Med. 1984; 12: 155-64.

25 Jones DA, Ainsworth BE, Croft JB, Macera CA, Lloyd EE Yusuf HR. Moderate leisure-time physical activity: who is 
meeting the public health recommendations? A national cross-sectional study. Arch. Fam. Med. 1998; 7: 285-9.

26 Stephens T, Jacobs DR Jr, White CC. A descriptive epidemiology of leisure time physical activity. Public Health Rep. 1985; 100: 147-58.

27 Bauman A, Owen N, Rushworth RL. Recent trends and socio-demographic determinants of exercise participation in Australia. Community Health Stud. 1990; 14: 19-26.

28 Owen N, Bauman A. The descriptive epidemiology of a sedentary lifestyle in adult Australians. Int. J. Epidemiol. 1992; 21: 305-10.

29 Barnekow-Bergkvist M, Hedberg G, Janlert U, Jansson E. Physical activity pattern in men and women at the ages of 16 and 34 and development of physical activity from adolescence to adulthood. Scand. J. Med. Sci. Sports 1996; 6: 359-70.

30 Vaz de Almeida MD, Graça P, Afonso C, D'Amicis A, Lappalainen R, Damkjaer S. Physical activity levels and body weight in a nationally representative sample in the European Union. Public Health Nutr. 1999; 2: 105-113.

31 King AJC, Coles B. The Health of Canada's Youth. Canadian Ministry of Supply and Services, H39-239/1992E, 1992.
32 Long BJ, Calfas KJ, Wooten WJ, et al. A multisite field test of the acceptability of physical activity counselling in primary care-Project PACE. Am. J. Prev. Med. 1996; 12: 73-81.

33 Booth ML, Bauman A, Owen N, Gore CJ. Physical activity preferences, preferred sources of assistance, and perceived barriers to increased activity among physically inactive Australians. Prev. Med. 1997; 26: 131-7.

34 Ferrini R, Edelstein S, Barrett-Connor E. The association between health beliefs and health behavior change in older adults. Prev. Med. 1994; 23: 1-5.

35 Eiser JR, Gable P. Health behavior as goal directed action. J. Behav. Med. 1988; 11: 523-35.

36 Silberstein LR, Striegel-Moore RH, Timko C, Rodin J. Behavioral and psychological implications of body dissatisfaction: do men and women differ? Sex Roles 1988; 19 219-32.

37 Siegel PZ, Brackbill RM, Heath GW. The epidemiology of walking for exercise: implications for promoting activity among sedentary groups. Am. J. Public Health 1995; 85 706-10. 


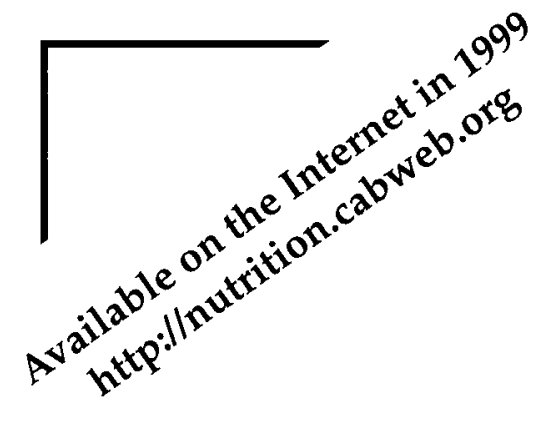

\section{Proceedings} of the Nutrition Society

\section{Editor: K M Younger Dublin, Ireland}

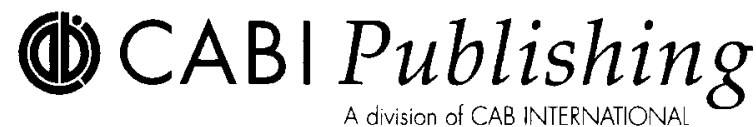

Throughout the year, the Nutrition Society holds important meetings and symposia, often in collaboration with other learned societies, where international experts are invited to speak on topics of particular interest in nutritional science.

The 1999 volume will feature papers and abstracts presented at Nutrition Society Symposia including:

- Meat or wheat for the next millennium?

- Effect of diet on lipoproteins involved in cardiovascular disease

- Bioavailability of micronutrients

- Optimal versus adequate nutrition

- Functionality of nutrients: behaviour, safety, gene expression and food technology

All this key information can be at your fingertips during 1999 by subscribing to the Proceedings of the Nutrition Society.

Published quarterly ISSN: $00296651 \quad$ 1999, Volume 58 $£ 240.00$ (US $\$ 425.00$ Americas only)

Order your 1999 subscription now!

(10) $\mathrm{CAB} \mid$ Publishing

$\mathrm{CAB}$ International

Wallingford, Oxon, OX10 8DE, UK

Tel: +44 (0)1491 832111

Fax: +44 (0)1491 829292

Email: publishing@cabi.org

\section{(1) CABI Publishing}

$\mathrm{CAB}$ International

10 East 40th Street, Suite 3203,

New York, NY 10016, USA

Tel: +1 (212) 4817018

Toll-free: 18005284841

Fax: +1 (212) 6867993

Email: cabi-nao@cabi.org 